\title{
A trajetória da personagem surdocega "Michelle" no filme Black pelo viés da filosofia linguística: do estado de indivíduo ao de sujeito
}

\section{The trajectory of character deaf-blind "Michelle" in movie Black trough the linguistic filosophy look: from status of individual to the subject}

\section{El trayectorio del carácter sordo-ciego "Michelle" en} película Black a través de la mirada lingüística filosofía: del estado del individual al sujeto

(iD) Maurício Moreira da Cruz Moreira Cruz.

Universidade Federal de Goiás (UFG), Goiânia, Goiás. Brasil.

E-mail: mauriciombi@hotmail.com

(iD) Ernandes da Silva Filho

Universidade Federal de Goiás (UFG), Goiânia, Goiás. Brasil. E-mail: ernandesf4@hotmail.com

iD Sebastião Elias Milani

Universidade Federal de Goiás (UFG), Goiânia, Goiás. Brasil. E-mail: sebaselias37@hotmail.com

iD@ Gláucia Vieira Cândido

Universidade Federal de Goiás (UFG), Goiânia, Goiás, Brasil. E-mail: glaucia_candido@ufg.br

Resumo: Este estudo objetiva observar e descrever a trajetória linguística de "Michelle", do filme Black, personagem que parte de um estado animal ao estado humano. Para tanto, a discussão, acerca de indivíduo e de sujeito, fundamenta-se em Condillac, Humboldt, Whitney, Saussure, Sapir, Chomsky, Herder, Bloomfield e Platão. Paralelo aos teóricos está 
a trajetória de "Michelle", que inicialmente é oprimida pela falta de entendimento de mundo ao seu redor, depois passa pelo aprendizado da língua e, finalmente, ao domínio da língua, ritmando-se rumo à coletividade. Foi possível constatar certa correspondência entre as discussões filosóficas e linguísticas e a referida obra cinematográfica.

Palavras-chave: Sujeito. Indivíduo. Historiografia. Filosofia linguística.

Abstract: This study observes anddescribes the linguistic trajectory of "Michelly", from movie Black, character who starts from an animal status, to human status. For this, the discussion about individual and subject is grounded in Condilac, Humboldt, Whitney, Saussure, Sapir, Chomsky, Herder, Bloomfield and Platão. Related with theorics, is "Michelly"'s trajectory, who in beginning was oppressed by fault of disagreement of world in your round, then pass through the learning of language, and finally to the language domain, going to the collectivity. It was possible to see a possible equivalence between philosophical and linguistic discussions and the cinematographic work referred.

Keywords: Subject. Individual. Historiography. Linguisticsphilosophy.

Resumen: Este estudio observa y describe la trayectoria lingüística de "Michelly", de película Black, personaje que parte de un estado animal, a un humano. Para esto, la discusión sobre individuo y sujeto se basa en Condilac, Humboldt, Whitney, Saussure, Sapir, Chomsky, Herder, Bloomfield y Platão. Relacionado con la teoría es la trayectoria de "Michelly", quien inicialmente es oprimido por la falta de comprensión del mundo en su ronda, luego pasa por el aprendizaje del lenguaje y finalmente al dominio del idioma, yendo a coletividad. Fue posible ver una posible equivalencia entre las discusiones filosóficas y lingüísticas y el trabajo cinematográfico referido.

Palabras clave: Sujeto. Individual. Historiografía. Filosofía lingüística.

Submetido em 16 de dezembro de 2019.

Aceite em 10 de junho de 2020.

Publicado em 12 de março de 2021. 
A trajetória da personagem surdocega "Michelle" no filme Black pelo viés...

Maurício Moreira da Cruz Moreira Cruz. • Ernandes da Silva Filho • Sebastião Elias Milani • Gláucia Vieira Cândido

\section{Introdução}

O filme Black, de 2005, do diretor Sanjay Leela Bhansali, bem recebido pela crítica e vencedor de melhor filme pelo National Film Awards em 2006, retrata a história de vida da personagem principal, "Michelle McNally", que em seu primeiro ano de vida se torna surda e cega. Com o passar do tempo, os pais da personagem não conseguem educá-la, tampouco ensinar-lhe os códigos de comportamento esperados pela sociedade, o que faz com que ela viva de modo "livre", imprevisível e arbitrário.

Após anos tentando entender a filha surdocega, apresentando-a aos médicos, aos psicólogos e aos psiquiatras, os pais recorrem, como uma última saída, a um professor chamado “Debraj Sahai". Ele tinha metodologias de ensino consideradas extremas que causaram espanto nos pais da estudante, mas que foram eficazes e necessárias, haja vista o desenvolvimento intelectual da personagem principal ao longo do filme.

Com o tempo, o professor consegue ativar na jovem a sua capacidade de linguagem, ou como defende Chomsky (1975a), a sua capacidade inata, que durante muito tempo se manteve em stand by. Isso ocorreu porque a falta de estímulo por parte da família para a aquisição da língua por "Michelle" fez com que a "ponte entre o sentido [...] e o sentimento concreto do sujeito no mundo" (SALOMÃO, 2016, p. 4) não se estabelecesse na personagem.

Assim, o filme permite que façamos uma espécie de analogia com a teoria linguística filosófica, uma vez que os status de "Michelle" demonstram ora um ser humano animal, incapaz de reflexão, ora um ser humano racional, com capacidade de entendimento de mundo. Por esse motivo, muito nos interessa essa obra cinematográfica, tal como o trabalho historiográfico de trazer a percepção de diversos autores sobre as noções de língua e pensamento.

O método historiográfico recai sobre este estudo devido à necessidade de observação das teorias linguísticas de forma abran- 
A trajetória da personagem surdocega "Michelle" no filme Black pelo viés...

Maurício Moreira da Cruz Moreira Cruz. • Ernandes da Silva Filho • Sebastião Elias Milani • Gláucia Vieira Cândido

gente, perpassando por autores diversos para uma ampla visão de um mesmo objeto de estudo, neste momento, o filme "Black", precisamente a personagem "Michelle". Com isso, investigaremos a retratação da vida da personagem pelo prisma das teorias de Condillac (1714-1780) [1780], Humboldt (1769-1859) [1836], Whitney (1827-1894) [1875], Saussure (1857-1913) [1924], Sapir (18841939) [1971], Chomsky (1928) [1975], Herder (1744-1803) [1770], Bloomfield (1887-1949) [1933] e Platão (2007).

Por isso, pretende-se trazer reflexões acerca da trajetória de vida de "Michelle", ao passar de um status de animal, ou filosoficamente, indivíduo, para uma posição de ser humano, sujeito. É esperado ainda fornecer elementos teóricos da filosofia linguística, discutir e comparar essas teorias e, assim, aplicá-las analogamente ao filme "Black".

\section{0 conceito de língua}

A discussão acerca do conceito de língua requer diferenciar o que é língua e o que é linguagem. Nesse sentido, Saussure (1924) apresenta o conceito de linguagem como uma faculdade mental ampla, que é naturalmente embutida em nós, enquanto que a língua é convencional e está subordinada a essa faculdade natural. Ao utilizar o nome "natureza/natural", Saussure não se referia ao fato de o aparato vocal estar naturalmente disposto para a realização da língua, mas sim, à ideia de que o "instinto natural" de linguagem provoca no ser humano a possibilidade de língua, não importando qual a modalidade da língua.

O linguista Whitney (1875) apresenta uma extrema concepção de que o aparelho vocal só foi utilizado por questões de decorrências inusitadas e de comodidade. Veja-se que, para ele, o ser humano poderia utilizar gestos para construção da língua. Destarte, ao usar imagens visuais em detrimento de imagens acústicas, o homem também constituiria a língua. 
A trajetória da personagem surdocega "Michelle" no filme Black pelo viés...

Maurício Moreira da Cruz Moreira Cruz. • Ernandes da Silva Filho • Sebastião Elias Milani • Gláucia Vieira Cândido

O autor do Curso de linguística geral, Saussure, assinala que, por diversos fatores, a língua não pode ser confundida com linguagem, visto a língua ser "um produto social da faculdade de linguagem e um conjunto de convenções necessárias, adotadas pelo corpo social para permitir o exercício dessa faculdade nos indivíduos" (SAUSSURE, 1924, p. 17), enquanto que a linguagem se define como sendo

multiforme e heteróclita; a cavaleiro de diferentes domínios, ao mesmo tempo física, fisiológica e psíquica, ela pertence além disso ao domínio individual e ao domínio social; não se deixa classificar em nenhuma categoria de fatos humanos, pois não se sabe como inferir sua unidade. (SAUSSURE, 1924, p. 17)

Humboldt (1836), por sua vez, agrega à língua a ideia de que ela se caracteriza como um armazém cultural da humanidade, servindo como meio de aprendizado do conhecimento, mas não trazendo o conhecimento em si. Seguindo o raciocínio do autor, a língua é aprendida socialmente, contudo, está disposta no ser humano, como se naturalmente pertencente a ele. Assim sendo, para Humboldt (1836), há no homem uma "língua interna", que se desenvolve pela sociedade, mas com a capacidade individual de cada falante. Para Whitney (1875), o conceito é "capacidade de linguagem", já para Saussure (1924), "capacidade de aprender uma língua”, já para Chomsky (1975a), "Gramática Universal”.

\section{Língua de sinais}

A respeito das línguas de sinais, devemos entendê-las como possuidoras de todos os níveis linguísticos analisáveis, tais como nas línguas orais. Assim, essa língua de modalidade viso-espacial, defende Quadros, apresenta características fonéticas, fonológicas e morfológicas em sua constituição, uma vez que: 
A trajetória da personagem surdocega "Michelle" no filme Black pelo viés...

Maurício Moreira da Cruz Moreira Cruz. • Ernandes da Silva Filho • Sebastião Elias Milani • Gláucia

Vieira Cândido

um sinal é resultado de combinações de unidades menores: a configuração da mão, o local de articulação e o movimento. Stokoe apresenta uma análise com base na simultaneidade, ou seja, as unidades são combinadas simultaneamente para a produção do sinal. (QUADROS, 2006)

A teoria de Whitney (1827-1894) (1875) traz respaldo às línguas de sinais, ao passo que, nessas línguas, o conceito e a imagem acústica dessa modalidade de língua não se dão mais desse modo, mas, sim, entre o conceito e a imagem visual. Por este motivo, o falante de línguas de sinais não concretiza seu pensamento por meio de pareamento entre imagens acústicas e conceitos (palavras), mas, sim, em imagens visuais e conceitos (sinais).

Na posição de língua materna, as línguas de sinais promovem o ato de comunicação aos surdos e aos surdocegos, já que essas línguas servem de instrumento para o surdo construir e desenvolver seu conhecimento plenamente, expressar conteúdos sutis, complexos ou abstratos. Trata-se de um dispositivo que possibilita o entendimento de todas as áreas do conhecimento humano, não restringindo a capacidade cognitiva do surdo ou surdocego; antes, oposto a isso, é o que amplia a gama de possibilidades de aprendizagem desses indivíduos. Desse modo, assim como toda língua natural,

a língua espaço-visual se utiliza de sistemas culturais e linguísticos para construir um sistema de significados, da mesma forma que os ouvintes se utilizam da língua oral auditiva. Ou seja, o consenso entre os pesquisadores é que, embora a língua de sinais seja uma modalidade linguística diferenciada, uma vez que utiliza o espaço para estabelecer a comunicação, isto não é empecilho para que ela seja considerada, assim como a oral auditiva, um instrumento semiótico [...] (FÁVERO; PIMENTA, 2006, p. 2) 
A trajetória da personagem surdocega "Michelle" no filme Black pelo viés...

Maurício Moreira da Cruz Moreira Cruz. • Ernandes da Silva Filho • Sebastião Elias Milani • Gláucia Vieira Cândido

Em verdade, todas as línguas do mundo podem se diferir no plano superficial, observando os níveis fonético-fonológico, morfológico, sintático. No entanto, em uma estrutura profunda, abstrata, todas as línguas se aproximam esquematicamente, trazendo traços mais ou menos relacionáveis. Isso porque a motivação de todas elas é a mesma, ou seja, a comunicação e a interação.

\section{A língua como formadora do ser humano}

Dado que a personagem "Michelle", de início, não possui uma língua, infere-se que ela não é, ainda, um ser humano. A fim de explicitar a necessidade da língua para formação plena do ser humano, discutiremos nesta seção a relação entre língua, sensação, conhecimento e sabedoria.

Inicialmente, a teoria de Platão elenca questões essenciais a respeito da língua como formadora de conhecimento. Isso porque, para ele, a língua é o próprio conhecimento, sem ela não há conhecimento. O ponto de partida são as sensações, uma vez que a língua nada mais é do que sensações nomeadas. Por esse motivo, a natureza de algo sempre é observada primeiro e, só posteriormente, o nome desse algo é apresentado.

No diálogo de Teeteto, Platão apresenta a metáfora das parteiras, que estabelece uma relação entre as parteiras de crianças (corpos) e os parteiros de seres humanos sábios (almas). Tal metáfora expõe a ideia do processo de criação de sábios, em que um sábio auxilia o outro, mas nunca realiza o próprio trabalho pelo outro, servindo tão somente como uma espécie de mediador.

Esse mesmo processo é claramente observado no decorrer do diálogo em questão, quando Sócrates auxilia Teeteto na passagem de conhecimento para sabedoria, visto ao longo do texto, em que Sócrates instiga através de perguntas a reflexão de Teeteto. Quando o filósofo interroga o jovem sobre o que é o conhecimento, e ele responde o que há e quantos há, Sócrates discute a questão da 
A trajetória da personagem surdocega "Michelle" no filme Black pelo viés...

Maurício Moreira da Cruz Moreira Cruz. • Ernandes da Silva Filho • Sebastião Elias Milani • Gláucia Vieira Cândido

metodologia para a construção do objeto. Quer ele ter do objeto "conhecimento" a sua definição, como explicita no trecho: "minha pergunta não visava a enumerá-los um por um; o que desejo saber é o que seja o conhecimento em si mesmo" (PLATÃO, 2007, p. 6).

Para Platão, é humano o indivíduo que pensa, que reflete, que tem conhecimento. Uma vez que a língua é o próprio conhecimento em si, não há possibilidade de um indivíduo tornar-se humano sem adquirir uma língua. Afinal, sem ela não há possibilidade de exposição do pensamento, dos desejos, dos argumentos em relação à situação, pessoa ou o objeto (que, por questões lógicas, sequer existiriam, dado que a língua é uma via de organização dos próprios pensamentos), tampouco assimilaria o conhecimento advindo de uma outra pessoa.

Sapir expõe que o "produto desenvolve-se com o instrumento". Desse modo, o pensamento só se desenvolve por meio da e através da língua, o que compactua com a ideia de que "o pensamento [...] é tão inconcebível sem a linguagem quanto o raciocínio matemático é impraticável sem a alavanca de um simbolismo matemático adequado" (SAPIR, 1971, p. 28).

A realização da língua se dá, primeiramente, pelas sensações, tal como mencionado anteriormente. Entretanto, Condillac (17141780) é quem, após Platão, dá seguimento às discussões a respeito das sensações, expondo que todos os conhecimentos vêm dos sentidos, os quais estão atrelados à noção de sensação. A diferença está na questão fisiológica e psicológica, respectivamente; os sentidos estão para a primeira questão, enquanto as sensações para a segunda. Para o autor, o sentido primário é o tato, ou seja, o ponto de partida para se situar no espaço, tocando e sentindo as texturas, consistências, calor, frio, enfim. Logo após, vem a visão, o paladar, o olfato e a audição.

De acordo com Condillac ([1780]1984), a língua só existe porque os sentidos possuem uma média, a qual é compartilhada com todos os seres humanos. Nesse sentido, todos esses cinco sentidos trabalham em conjunto para a construção linguística dos se- 
A trajetória da personagem surdocega "Michelle" no filme Black pelo viés...

Maurício Moreira da Cruz Moreira Cruz. • Ernandes da Silva Filho • Sebastião Elias Milani • Gláucia Vieira Cândido

res humanos. O autor ainda tem a ideia de alma constantemente ligada às sensações, pois, segundo o autor, "é a alma que sente; somente a ela as impressões pertencem; e sentir é a primeira faculdade que notamos nela" (OS PENSADORES, 1984, p. 65).

Apesar de Condillac (apud CAIXETA, 2003) defender os sentidos como cruciais para o conhecimento, o autor ainda argumenta que não depende somente deles para se alcançar plenamente o conhecimento, mas também da forma como cada indivíduo reflete e absorve cada sensação, tal como no trecho a seguir:

[...] o fato de vermos e ouvirmos não são garantia de conhecimento dos objetos. Em outras palavras, não basta possuir os sentidos, pois mesmo aqueles que os possui não gozam do mesmo conhecimento. A posse do conhecimento resulta das diferentes maneiras pelas quais utilizamos os sentidos. (CAIXETA, 2003, p. 6)

Herder (1744-1803) ([1770]1982) também contribui teoricamente sobre o conceito de sensações, dado que o autor defende a lei natural imediata, entendendo que o ser humano não consegue se desprender de suas sensações ou bloqueá-las, visto que, de acordo com a lei da natureza, ele é um ser sensível. No entanto, é característica exclusiva do ser humano o ato de refletir sobre os sentidos; é o que o diferencia dos demais animais, uma vez que os animais se deixam guiar pelos sentidos. Assim, em relação aos animais, fala-se de instintos, não de sensações. Nesse momento, há a passagem do natural para o artificial, pois, o homem deixa de ser animal natural e passa a adquirir a língua que é natural ao homem, porém artificial em relação aos animais e ao que é posto pelo natural.

A razão só é alcançada pelo ser humano devido ao seu afastamento dos sentidos animais - tato, olfato, paladar, audição e visão - não excluindo o seu uso, mas, sim, atribuindo a eles um caráter reflexivo, como modo natural de formular informação por meio da língua artificial humana. Sobre a língua humana, Herder 
A trajetória da personagem surdocega "Michelle" no filme Black pelo viés...

Maurício Moreira da Cruz Moreira Cruz. • Ernandes da Silva Filho • Sebastião Elias Milani • Gláucia Vieira Cândido

([1770]1982) defende que ela é natural ao homem e, por este motivo, tem-se o ser humano como um ser cuja capacidade efetiva é exteriorizar um escopo mais amplo, uma mente iluminada e capaz de organizar e assimilar informações.

\section{Indivíduo e sujeito}

A discussão em relação aos conceitos de indivíduo e sujeito se iniciou com o próprio Platão, utilizando nomenclaturas diferentes, mas com conceitos parecidos. Trata-se de algo recorrente no fazer científico, assim como Lavoisier defende, ao afirmar que "nada se cria, tudo se transforma". Torna-se, então, irrelevante discutir o nome, e impreterível discutir os conceitos.

O indivíduo é o corpo, e por meio dele é que se desenvolve o sujeito. Portanto, o sujeito é indubitavelmente cultural, político, ideológico, enfim, como a noção de alma para Platão, e o indivíduo, o próprio corpo em que residem os sentidos. Esses dois conceitos são indissociáveis, visto que no plano concreto, por meio de Kant (1714-1804) (1980) e a crítica da razão pura, o que existe é o indivíduo, ou seja, o corpo. Logo, o tornar-se sujeito se dá pela língua, pois sem ela, nada existe. A falta de entendimento do mundo que o cerca, coloca o indivíduo em uma posição de oprimido, tal como quem não domina uma língua, sendo oprimido por ela.

Humboldt (1767-1835) (1836) também discorre a respeito desse dualismo, contudo, ele se apropria dos termos "indivíduo" e "homem", estando este relacionado com a cultura e a sociedade, e aquele com a natureza de animal. Para o linguista, é preciso haver uma equidade interexistencial do sujeito e do indivíduo, porque sem indivíduo o sujeito não poderia existir, e sem sujeito o indivíduo continuaria como um animal da natureza, porém, não cultural.

Por mais que Bloomfield (1887-1949) ([1933]1984) desenvolva apenas a noção de indivíduo, ele considera que o indivíduo é 
A trajetória da personagem surdocega "Michelle" no filme Black pelo viés...

Maurício Moreira da Cruz Moreira Cruz. • Ernandes da Silva Filho • Sebastião Elias Milani • Gláucia Vieira Cândido

aquele que é o membro da comunidade, que aprende a língua por hábito ou imitação. O primeiro contato do indivíduo com a língua será, então, com a família. No entanto, após ingressar na escola, esse modelo de língua é rompido, uma vez que na escola existem diversas possibilidades de usos da língua. Neste momento, o indivíduo passa a influenciar e ser influenciado pela língua ali exposta.

Bloomfield ([1933]1984) não considera que a vida do indivíduo possa ser influenciada pela comunidade, porque, para o autor, não existe o "assujeitamento" e, por isso, a não existência do sujeito, somente a consideração do indivíduo, que está para e na sociedade. Ele é membro dela, ele possui a autonomia de modificar a língua, entretanto é a própria sociedade que estabiliza a língua, definindo e convencionando relações mais estáveis.

\section{6 "Michelle" como indivíduo e sujeito}

Uma vez observados os conceitos de sujeito e indivíduo, é possível, analogamente, relacionar o estado da personagem "Michelle" tanto com o primeiro quanto com o segundo conceito. Se fizermos um recorte temporal da vida da personagem no filme, teremos, no primeiro plano, Michelle desde o nascimento até a pré-adolescência e, no segundo, ela já na adolescência até a juventude.

No primeiro período, essa personagem supracitada não desenvolve suas capacidades cognitivas, intelectuais e linguísticas, dado que "Michelle" era tratada como um ser indomável e imprevisível, portanto, incapaz de agir perante às regras e convenções da família, tampouco da sociedade. Consequentemente, ela não possuía também conhecimento, pois este está na sociedade, e só por meio da língua é observável e exequível plenamente.

Neste status de indivíduo, a personagem não entendia suas sensações, e suas ações eram guiadas por elas. Confusa, Michelle agia conforme seus sentidos a conduziam; por exemplo, caso quisesse comer algum alimento, sentia o cheiro (olfato) para detectar 
A trajetória da personagem surdocega "Michelle" no filme Black pelo viés...

Maurício Moreira da Cruz Moreira Cruz. • Ernandes da Silva Filho • Sebastião Elias Milani • Gláucia Vieira Cândido

se era de seu agrado, pegava (tato) pela mão e introduzia na boca (paladar). Ela sentia, é certo, que algo estava quente ou frio, as texturas possíveis, áspero, liso; sentia o gosto, se era doce, salgado, amargo, azedo etc., ainda que não soubesse nomear nenhuma dessas sensações nem entendê-las.

Essa é uma característica dos animais, que se deixam guiar por suas sensações ou sentidos, não refletindo sobre ou não categorizando cada uma delas. É a partir do entendimento das sensações que os seres humanos ou sujeitos passam a conviver em sociedade e, dessa convivência, surge a necessidade de comunicação, por isso, da língua. É nesse momento que, defende Herder ([1770]1986), o homem "cria" uma língua artificial, com finalidade na comunicação. Vale ressaltar que não houve um momento específico em que o homem decidiu sobre a criação da língua, mas que essa ocorrência se deu naturalmente, assim como é natural ao homem andar, comer, entre outras ações.

Já na segunda instância da vida de "Michelle", é observável o desenvolvimento da personagem ao adquirir a língua de sinais tátil. Logo, ela assimila a língua e passa a entender, criar e externar seus pensamentos através dela. Assim, a personagem deixa de ser um indivíduo que não faz parte da sociedade, que não interfere na coletividade de sua comunidade e passa a se integrar como um sujeito que altera e é alterado pela sociedade.

Ao encontro da teoria de Condillac (1754), é notório que, sem as sensações, o indivíduo não pode virar um sujeito. Exatamente aí recai a importância das sensações de "Michelle", por mais que, inicialmente, não fossem condicionadas a um pensamento organizado, mostraram-se cruciais para seu desenvolvimento como sujeito inserido no mundo. Fato é que os sentidos não são substituíveis. Desse modo, a visão jamais substituirá a posição da audição, nem do olfato, paladar, ou tato, no entanto, existe a possibilidade de adaptação dos sentidos para uma aproximação da função de um outro ausente. Assim, observa-se no filme que a personagem principal adaptou alguns de seus sentidos (visíveis 
A trajetória da personagem surdocega "Michelle" no filme Black pelo viés...

Maurício Moreira da Cruz Moreira Cruz. • Ernandes da Silva Filho • Sebastião Elias Milani • Gláucia Vieira Cândido

na obra cinematográfica apenas o tato, olfato e paladar) para compensação da falta da visão e da audição.

A correlação entre forma e significado permitiu que a personagem ativasse a língua internalizada e ainda não acionada. Ao observar, no filme, que o professor "Debraj Sahai" ensinou, estimulou e relacionou os signos linguísticos na personagem por intermédio dos sentidos pertencentes a ela, confirmamos a tese de que, inicialmente, temos a natureza de algo, ou a forma e, posteriormente, o nome desse algo, ou o significado. Essa relação simbólica se dá pela língua, que pereniza e atualiza constantemente o pensamento, e é também atualizada por ele.

O que se pôde observar, então, foi a concordância do que ocorreu com a personagem, com a noção de "capacidade de linguagem" de Chomsky (1975a), uma vez que, mesmo aprendendo tardiamente a língua de sinais tátil, “Michelle” possuía latente, em sua essência, a sua capacidade de linguagem. Tanto seu input, quanto seu output foram desenvolvidos ao adquirir a língua. Portanto, foi possível verificar que

a capacidade da linguagem, herança da espécie, permite a produção de infinitas representações, através das quais os sujeitos se conhecem e se dão a conhecer, ajustam a situação em que se encontram a conhecimentos previamente acumulados, e criam novos conhecimentos. (SALOMÃO, 1999, p. 14).

Ademais, a personagem principal do filme "Black" enfrentou três estágios da aprendizagem da língua. O primeiro, o da língua como instrumento de opressão, instância na qual se hospeda o indivíduo que não domina a língua ou não a possui. O segundo, a língua como modo de classificação, em que o usuário dela passa a compreender os processos fundamentais da língua e inicia o processo metalinguístico. Por último, o momento da língua como libertação, quando o sujeito falante a domina, por meio do plano do discurso, exprimindo suas ideias e pensamentos, conforme as possibilidades que essa língua lhe apresenta. 
A trajetória da personagem surdocega "Michelle" no filme Black pelo viés...

Maurício Moreira da Cruz Moreira Cruz. • Ernandes da Silva Filho • Sebastião Elias Milani • Gláucia

Vieira Cândido

\section{Considerações finais}

O dualismo entre indivíduo e sujeito nos permitiu observar com mais clareza os estágios da personagem "Michelle", ao passo que a vida dela também trouxe uma aplicabilidade às teorias dos autores anteriormente observados. Por este motivo, foi relevante constatar o ponto em que teoria e prática se fundem, possibilitando a concretização do conhecimento de modo empírico e por meio de analogias, processos fundamentais para o pesquisador.

Após uma breve reflexão, é possível inferir que o pensamento se dá apenas por meio da língua. Do contrário, são apenas abstrações inominadas que se perdem. No filme Black (2005), dirigido por Sanjay Leela Bhansali, certamente há uma adaptação, no entanto, "preto" ("black") era como se nomeava o pensamento que a personagem "Michelle" possuía, que condiz com a ideia de que sem língua nada existe.

Dado o exposto, foi possível perceber como a língua se faz impreterível na construção de um ser humano. Ela não só atualiza o pensamento humano, como também é atualizada por ele. É assim uma relação de interdependência, em que um sujeito não existe sem língua, e a língua também nunca existiria sem a existência de um sujeito.

\section{Referências bibliográficas}

BLACK. Direção: Sanjay Leela Bhansali, Produção: Sanjay Leela Bhansali. Índia, Yash Raj Films, 2005.

BLOOMFIELD, L. Language. Chicago: Editora Chicago Press, 1984.

CAIXETA, M. E. Condillac e o ensino de ciências: que relações podemos encontrar ainda hoje? Rev. Ensaio, Belo Horizonte, v. 05, n. 01, p. 26-41, Março, 2003. 
A trajetória da personagem surdocega "Michelle" no filme Black pelo viés...

Maurício Moreira da Cruz Moreira Cruz. • Ernandes da Silva Filho • Sebastião Elias Milani • Gláucia Vieira Cândido

CHOMSKY, N. Reflexões sobre a linguagem. Trad. Isabel Gonçalves. Lisboa: Edições 70, 1975a.

FÁVERO, M. H.; PIMENTA, M. L. Pensamento e Linguagem: a língua de sinais na resolução de problemas. Psicologia: Reflexão e Crítica. 2006, v. 19, n. 2, p. 225-236. ISSN 0102-7972.

HERDER, J. G. Obra selecta. Madrid: Alfaguara, 1982.

HUMBOLDT, W. K. V. Sobre la diversidad de la estrutura del lenguaje humano y su influencia sobre el desarrollo espiritual de la humanidad. Barcelona: Anthropos, 1990.

KANT, I. Crítica da razão pura. Trad. Valério Rohden e Udo B. Moosburger. São Paulo: Abril Cultural, 1980.

OS PENSADORES. Condillac, Helvéticus e Degerando. Textos escolhidos. São Paulo: Abril Cultural, 1984.

PLATÃO. Diálogos I: Teeteto (ou Do conhecimento), Sofista (ou Do ser), Protágoras (ou Sofistas) Bauru: Edipro, 2007.

QUADROS, R. M. d. (2006). Efeitos de modalidade de língua: as línguas de sinais. ETD - Educação Temática Digital, 7(2), 168-178, Campinas, v. 7, n. 2, p. 168-178, jun. 2006 - ISSN: 1676-2592.

SALOMÃO, M. M. A questão da construção do sentido e a revisão da agenda dos estudos da linguagem. Revista Veredas, Juiz de Fora, v. 03, n. 1, p. 61-79. jan/jun. 1999.

SAPIR, E. A linguagem: introdução ao estudo da fala. 2. ed. Rio de Janeiro: Livraria Acadêmica, 1971.

SAUSSURE, F. Curso de lingüística geral. 6. ed. São Paulo: Editora Cultrix, 1924.

WHITNEY, William D. La vie du langage. Paris: Germer, 1875 